\title{
Identity Development \& Affect of Labelling in Transgender Children
}

\author{
Vishakha Tyagi ${ }^{1}$, Gaurav Singh Bhati ${ }^{2}$, Ronak Tyagi ${ }^{3}$ \\ ${ }^{1} \mathrm{PG}$ - Community Science, MPUAT University, Udaipur, Rajasthan \\ ${ }^{2} \mathrm{PG}$ - EEE Department, IIT, Guwahati, Assam \\ ${ }^{3}$ UG - BBa-LL.B, UPES, Dehradun, Uttarakhand
}

\begin{abstract}
Transgender people can be found on quite wide spectrum all over the world. The need to understand this neglected section of the society has now been coming to light even though still majority of educators, policy makers and researchers do not consider all due components that would help to best understand the factors that influence their life specifically discussing growth. The process of the development of identity among these children as they develop at their parental home and many times at other places majorly differs than that of cisgender children"s. This review article intends to give a peek into lives of these people, their identity development as they grow and how the conventional act of labelling makes an impact on them.
\end{abstract}

Keywords: Transgender Children, Child development, Self-concept, Gender Identity among Transgender Children, Identity development during Childhood.

\section{INTRODUCTION}

The term 'trans' means beyond or across and gender refers to the socially accepted roles, views, beliefs and presentation of these in accordance to the sex assigned to an individual at the time of birth. The term transgender is an umbrella termmeaning that the term has many people covered under it whose identity, expression or manifestation of gender does not fit into the typical socially identified genders i.e., male and female. The term was first given by Psychiatrist John F. Oliver in 1965.

As soon as a child is born into a family, he is consistently taught to be associated by one of the two customarily known traditional genders usually by expressing own identity via various means such as by referring to he/she, by style of clothing, grooming, choice of toys, activities, plays etc. The sense of gender identity starts as early as two years and the dissimilarity and disintegration can be felt at as young as three years old to some and for the others in early adolescent years (Pardo, 2008).

As the individual grows up, there is a need for identity development that begins soon during late adolescent years continuing upto early adulthood period and there is a felt need to conform with the roles assigned to a person individually and socially in order to seek acceptance by the society. Transgenders who face confusion and the feeling of gender dissonance starting from the school years face a difficult and challenging situation as they move towards the puberty which brings even more challenging feelings and the adolescent may become gender dysphoric, may also face various kind of problems which cisgendered adolescents do not defy. The need for right type of parenting and guidance for such children cannot be stressed enough as the right treatment at early years impact the individual's mental, psychological, social and overall well being for the rest of their life. There is an immense need to address the studies which describes the situation empirically.

\section{IDENTITY DEVELOPMENT THROUGHOUT CHILDHOOD}

Some individuals don't recognise their gender in congruence with the sex they were assigned at birth. It might be possible for some people to have been born with a penis, and appointed as a male at birth, but over the time realize that they associate themselves to women and typical social standards of masculinity or femininity do not apply to them. Such individuals are adopting in figures of gender identity and expression that are not affiliated to their body parts or what sex a doctor decided they are at birth (Lopez, 2017). All children whether transgender or not are at serious risk for dilemma and might be at a critical point when their true sense of identity is discouraged and not critically understood (Forcier, 2020) as they grow older. If they continue to feel misunderstood while growing up, they eventually are in need of medical care due to mental issues (Clark et al., 2014). The identity and self esteem in young children develop as they develop attitudes, values and categories that they associate themselves to. As projected by the society they find a need to label 


\section{International Advanced Research Journal in Science, Engineering and Technology}

Vol. 8, Issue 6, June 2021

\section{DOI: $10.17148 /$ IARJSET.2021.8637}

themselves by their age, gender and other characteristics. The children's self-concept is explained by these labels in very concrete manner (Oswalt)

Traditionally the society has at all times in past associated roles and behaviours to stereotypical frontier of masculine and feminine which limit the child's interests and curiosity because of the need to play it by the book. Such demarcating factors are unfavourable because they tend to confine the purview of practicing various skills, talents and genuine interests. The repercussion being, the child may never get a chance at exploring his true inner potential. As an outcome they either face discrimination as well as criticism for aspiring what do not comply to society's conscious viewpoint or child may simply make peace with pressure and never feel comfortable or good about pursuing it (Rafferty, 2018). Such practices affect a child's identity formation from the very early years of his development and as child becomes an adult, the person might not feel content with his identity which has been shaped largely by society's assumptions of who one should be, therefore is not his own true identity.

Due to insufficient models or ideas of their identity development, transgender children don't get much to guide them into elder wise versions of themselves, there is a lack of information for aspiration. A study by Mcgillivray \& Jennings (2008) revealed that the teacher's training textbooks rarely addressed the transgender people as well as their experiences. Ringo 2002, found that the public perception of transgender were both positive as well as negative, reflecting an impact on child's behaviour as he/she grows up in the society as a result, these people have to pretend a distorted image of themselves that their inner self does not agree to. Cromwell (1999), Green (2004) and Kailey (2005) found that transgender people might change or alter their public manifestations for different social purposes such as protection from harassment, invalidation and judging attributes not entirely like cisgender but only requisitely.

\section{IS THERE A NEED TO LABEL GENDER?}

Roberts, suggests that the affects of being gender non-conforming seeping forth to elevated level of stress inflicting into PTSD and abused victimization and also puts children at higher risk for physical, psychological and sexual abuse (Pediatrics, 2012). Exposure to childhood physical, psychological, and sexual abuse, and probable PTSD were elevated in youth in the top decile of childhood gender nonconformity compared with youth below median nonconformity. Gender nonconformity predicted increased risk of lifetime probable PTSD in youth after adjustment for sexual orientation. From a study conducted by APA ,1994 it was concluded that in case of gender non-conforming children and adolescents, the Gender Identity Disorder criteria are significantly broader in scope than in earlier revisions. According to the advocates of trans family and the Trans allies suggest that our understanding of gender in rigid binary framework causes social fear that leads to misinformation and results in crime, violence and discrimination (Pardo, 2008) if a gender neutral or non gender base line will began then that can provide a platform for less-gendered or gender oriented discrimination and stabilization of gender discrimination free or non especial labelling and likewise treating society giving transgenders a free and wider growing acceptance of their identity. Paz Galupo, et al. (2016) described that, 'The Labels do not Work Very Well'. The study called attention to the transgender individual conceptualisations of sexual orientation and sexual identity. The study focused on the conceptualisation of sexual orientation in transgender adults by exploring the sexual identity label they choose. The number of participants was 172 who were form U.S. and lied between the age range of 18-65, who self-identified as transgender, transsexual, gender variant or having a transgender history. Qualitative responses were analysed through thematic analyses. 6 themes were identified related to transgender individual's descriptions of their sexuality namely, (1) trans sexuality as complex; (2) shifts in trans sexuality; (3) focus on beloved; (4) relationship style and status; (5) sexuality, bondage \& discipline / domination \& submission / sadism \& masochism (BDSM), and kink; and (6) separating sexual and romantic attraction. Because the categories LGBTQAA+ does not define a fine difference in the subjectivities on a gender continuum so there can be misrepresentation of identification of people who are marginalised due to their sexuality. Because often gender and sexual orientation are perplexed and often assumptions are made regarding which results in them being demented. Having a comprehensible identity would make it serene and directed efforts made towards the welfare of certain needy groups such as through policies projects, campaigns etc (Institute of Development Studies).

\section{CONCLUSION}

As the identity plays a determining role in assisting development of an individual, it is of prime importance that the identity formation should be established at right age clock, for overall achievement of developmental milestones coming ahead in life. Successful achievement of both self-identity as well as social identity and equilibrium between the two keeps the mental and psychological balance maintained. The exigency to name or label the gender is still an issue of debate but there's another context to the picture of creating a gender-neutral society and all living as individuals who are gainfully contributing members of the society. In an individual's life all familial and societal aspects along with racial, religious, ethnic and occupational factors play affecting role therefore family programs and social institutions should 


\section{International Advanced Research Journal in Science, Engineering and Technology}

Vol. 8, Issue 6, June 2021

\section{DOI: $10.17148 /$ IARJSET.2021.8637}

work in a manner to help transgender children achieve their identity in optimising manner so they can achieve sense of concrete self and get hold of the totality of one's self construct.

\section{REFERENCES}

[1]. Roberts, A. Rosario, M. Corliss, H. Koenen, K. Austin, S. (2012). Childhood gender nonconformity: a risk indicator for childhood abuse and posttraumatic stress in youth. Austin Official Journal of the American Academy of Pediatrics, 129 (3) 410-417.

[2]. Macgillivray, I., \& Jennings, T. (2008). A content analysis exploring lesbian, gay, bisexual, and transgender topics in foundations of education textbooks. Journal of Teacher Education, 59, 170-188

[3]. Paz Galupo M, Shane BH and Nicholas LM, 2016. The Labels don't Work Very Well: Transgender individuals' conceptualizations of sexual orientation and sexual identity. International Journal of Transgenderism, Vol. 17, No. 2, pp. 93-104.

[4]. Ringo,. P. (2002). Media roles in female to male transsexual and transgender identity formation. International Journal of Transgenderialism, 6(3)

[5]. Cromwell., J. (1999). Transmen and FTMs: identities bodies genders and sexualities. Chicago, IL: University of Illinois Press.

[6]. Green, J. 2004. Becoming a visible man. Nasville, Vanderbilt University Press.

[7]. Kailey, M. (2005). Just add hormones. An insiders guide to the transsexual experience. Boston, MA. Beacon Press.

[8]. Seth T. Pardo(2008). Growing Up Transgender: Research and Theory March 2008 by ACT for Youth Center of Excellence

[9]. Oswald, A. (2020). Early childhood emotional and social development: identity and self-esteem. Gulf bend center. Msw.

[10]. Schneeberger Ar 2014, Schneedberger AR 2014, Clark TC2014, Simons L 2013, Robinson JP 2013

[11]. Forcier, M. (2020). Gender Identity Development in Children and Adolescents. Alpert School of Medicine Brown University.

[12]. Rafferty, J. (2018). Gender Identity Development in Children. American Academy of Pediatrics. Retrieved on 4 May 2020, from https://www.healthychildren.org/English/ages-stages/gradeschool/Pages/Gender-Identity-and-Gender-Confusion-In-Children.aspx

[13]. Lopez, G. (2017). Questions about gender identity and being transgender you were too embarrassed to ask. Retrieved from https://www.vox.com/2015/4/24/8483561/transgender-gender-identity-expression. 